\title{
Gérard Bouchard
}

Sociologue - historien, Université du Québec à Chicoutimi

(2007)

\section{"L’AVENIR DE LA CULTURE QUÉBÉCOISE: QUELS SONT LES RÊVES COLLECTIFS ? La culture québécoise est-elle en crise?"}

\author{
Un document produit en version numérique par Jean-Marie Tremblay, bénévole, \\ professeur de sociologie au Cégep de Chicoutimi \\ Courriel: jean-marie_tremblay@uqac.ca \\ Site web pédagogique : http://www.uqac.ca/jmt-sociologue/ \\ Dans le cadre de la collection: "Les classiques des sciences sociales" \\ Site web: http://classiques.uqac.ca/ \\ Une collection développée en collaboration avec la Bibliothèque \\ Paul-Émile-Boulet de l'Université du Québec à Chicoutimi \\ Site web: http://bibliotheque.uqac.ca/
}


Cette édition électronique a été réalisée par Jean-Marie Tremblay, bénévole, professeur de sociologie au Cégep de Chicoutimi à partir de :

Gérard Bouchard

“L’avenir de la culture québécoise: quels sont les rêves collectifs ? La culture québécoise est-elle en crise?"

Un article publié dans Que devient la culture québécoise ? Que voulons-nous qu'elle devienne? pp. 28-29. Un cahier spécial de 1'Institut du Nouveau Monde inséré dans le journal Le Devoir, Montréal, dimanche le 20 janvier 2007.

Historien et sociologue, Université du Québec à Chicoutimi, directeurfondateur de l'Institut interuniversitaire de recherches sur les populations. Auteur de très nombreux ouvrages.

[Autorisation accordée par le M. Bouchard de diffuser cet article dans Les Classiques des sciences sociales le 23 janvier 2007.]

Courriel : Gerard Bouchard@uqac.ca

Polices de caractères utilisée :

Pour le texte: Times New Roman, 14 points.

Pour les citations : Times New Roman, 12 points.

Pour les notes de bas de page : Times New Roman, 12 points.

Édition électronique réalisée avec le traitement de textes Microsoft Word 2004 pour Macintosh.

Mise en page sur papier format : LETTRE (US letter), 8.5' $\mathrm{x} 11$ '')

Édition numérique réalisée le 24 janvier 2007 à Chicoutimi, Ville de Saguenay, province de Québec, Canada. 
CAHIER SPÉCIAL Télécharger le cahier spécial de l'Institut du DE L'INSTITUT Du Nouveau Monde, Que devient la culture quéNOUVEAU MONDE bécoise? Que voulons-nous qu'elle devienne?

http://www.inm.qc.ca/pdf/cahierspecial2007.pdf 


\section{Gérard Bouchard (2007)}

"L’avenir de la culture québécoise: quels sont les rêves collectifs?

La culture québécoise est-elle en crise ?"

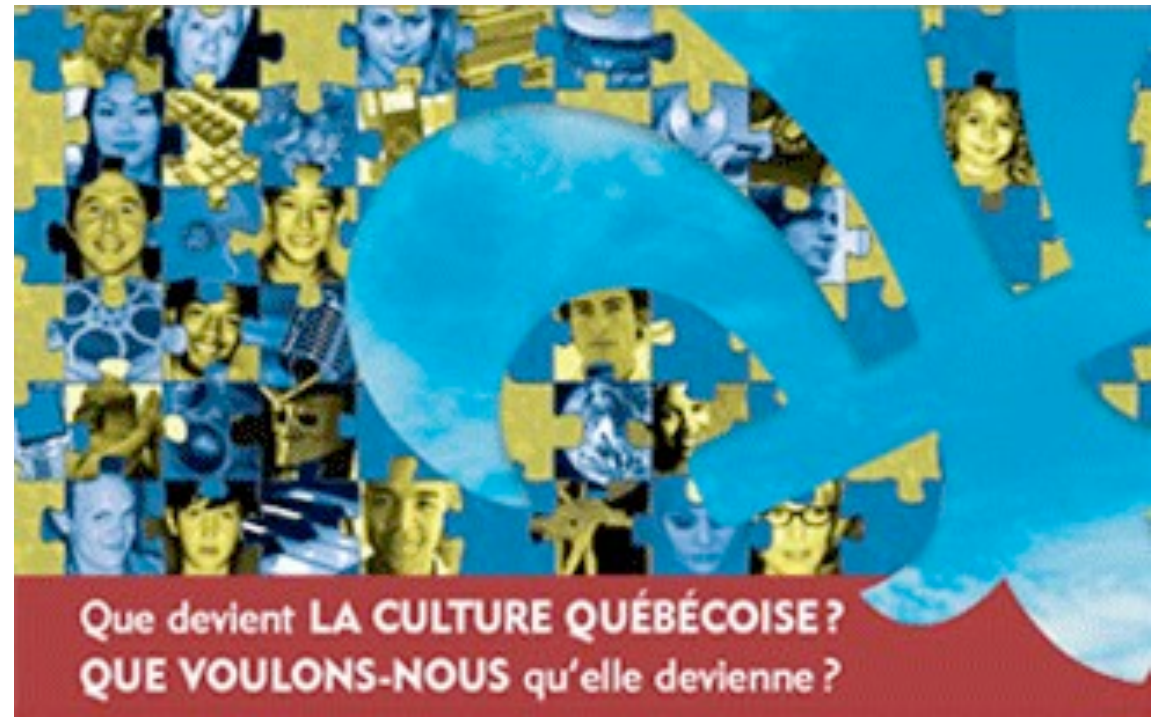

Un article publié dans Que devient la culture québécoise? Que voulons-nous qu'elle devienne? pp. 28-29. Un cahier spécial de l'Institut du Nouveau Monde inséré dans le journal Le Devoir, Montréal, dimanche le 20 janvier 2007. 
Gérard Bouchard

“L’avenir de la culture québécoise: quels sont les rêves collectifs ?

La culture québécoise est-elle en crise ?"

Un article publié dans Que devient la culture québécoise? Que voulons-nous qu'elle devienne? pp. 28-29. Un cahier spécial de l'Institut du Nouveau Monde inséré dans le journal Le Devoir, Montréal, dimanche le 20 janvier 2007.

Depuis quelques décennies, de nombreux intellectuels européens, notamment français, ont affirmé que la civilisation occidentale était en crise : fin des "grands récits », des grandes idéologies et utopies qui ont soutenu le développement de l'Ouest au cours des deux ou trois derniers siècles; rupture avec les traditions gréco-romaine et judéochrétienne ; mémoire douloureuse des horreurs du XXe siècle (génocides, totalitarismes, colonialismes...) ; déception, désarroi même devant une histoire qui n'a pas tenu ses promesses et qui semble maintenant se défaire, annonçant peut-être un nouveau cycle de violence et de guerres ; perte des repères, des croyances, des idéaux ; aggravation des signes d'anomie sociale (suicide, criminalité, désaffection institutionnelle, etc.). Il s'est ainsi créé un vide que met à profit une commercialisation à outrance, accélérant ainsi le déclin de l'ancien humanisme et accentuant les symptômes de crise.

Tel est, sommairement résumé, le diagnostic qui semble rallier la majorité des esprits. À ce propos, deux questions se posent. Dans quelle mesure ce diagnostic très sombre résiste-t-il à un examen critique ? Et qu'en est-il, plus précisément, de la culture québécoise? 


\section{Un problème de définition}

Si l'on veut éviter l'arbitraire, il importe d'abord de bien définir les termes et de se donner quelques indicateurs. D'abord, par la notion de culture, on entendra ici un ensemble de représentations largement partagées (valeurs, croyances, idéaux, identités) qui constituent les fondements symboliques d'une collectivité. Nous voilà dans le domaine de l'imaginaire collectif, à savoir le capital symbolique qui, dans toute société, four nit une définition de Soi et de l'Autre, propose une vision du passé, une mémoire, de même qu'une vision de l'avenir (notamment par le biais d'utopies) et, finalement, opère une appropriation de l'espace qui se trouve ainsi transformé en un territoire, c'est-à-dire un espace parcouru, nommé, raconté, etc. Il s'agit, en d'autres mots, d'un ensemble de repères qui permettent aux individus et aux collectivités de se situer par rapport aux autres, de s'insérer dans le temps et dans l'espace et de se gouverner. Il va de soi, par ailleurs, qu'une même société peut être le lieu de plus d'un imaginaire qui se déploient en complémentarité ou en concurrence et peut-être même en contradiction. Ce qu'il faut retenir, c'est que tout imaginaire collectif comme aussi toute culture - est soutenu par des mythes. Ce mot est souvent galvaudé, assimilé soit à de pures affabulations, soit à des distorsions délibérées et malicieuses de la réalité, soit encore à des délires collectifs pouvant conduire à des actes monstrueux. Il arrive en effet au mythe de se présenter sous ces traits ; l'observation de la vie quotidienne, tout comme l'histoire, en fournissent bien des exemples. Mais le mythe ne se réduit pas à cela, on aurait tort de le confondre avec ses dérapages. Il faut insister ici sur trois points.

Premièrement, dans sa réalité profonde, le mythe est une représentation a) qui institue une signification associée à une valeur, une croyance, un idéal ; b) qui s'incarne dans un événement historique, dans un lieu, un objet, un personnage ou une institution; c) qui est l'objet d'un processus de ritualisation en vertu duquel il acquiert un statut de quasi-tabou; et d) qui mobilise les esprits, incite à l'action. En deuxième lieu, sa propriété principale tient dans son efficacité, dans sa capacité de mobiliser des individus et des groupes autour d'un symbole, d'une finalité, comme on le voit dans le mythe du multiculturalisme au Canada anglais, dans l'ancien mythe de la survivance 
au Canada français, dans le mythe de la frontière aux États-Unis, dans le mythe républicain en France, dans le mythe indigéniste au Mexique, dans le mythe de la démocratie raciale au Brésil, etc. Enfin, c'est bien en vain qu'on voudrait éradiquer le mythe pour en épurer la culture, sous prétexte qu'il est un mode vulgaire et dangereux de connaissance ou de perception. Car le mythe est indélogeable ; depuis des millénaires, il renaît sans cesse de ses cendres, il est présent dans toutes les sociétés, il est une catégorie fondamentale de la conscience. On ne choisit pas de faire avec ou sans le mythe, il s'impose toujours à nous, sous une forme ou sous une autre - ce qui n'exclut pas qu'on puisse agir sur lui.

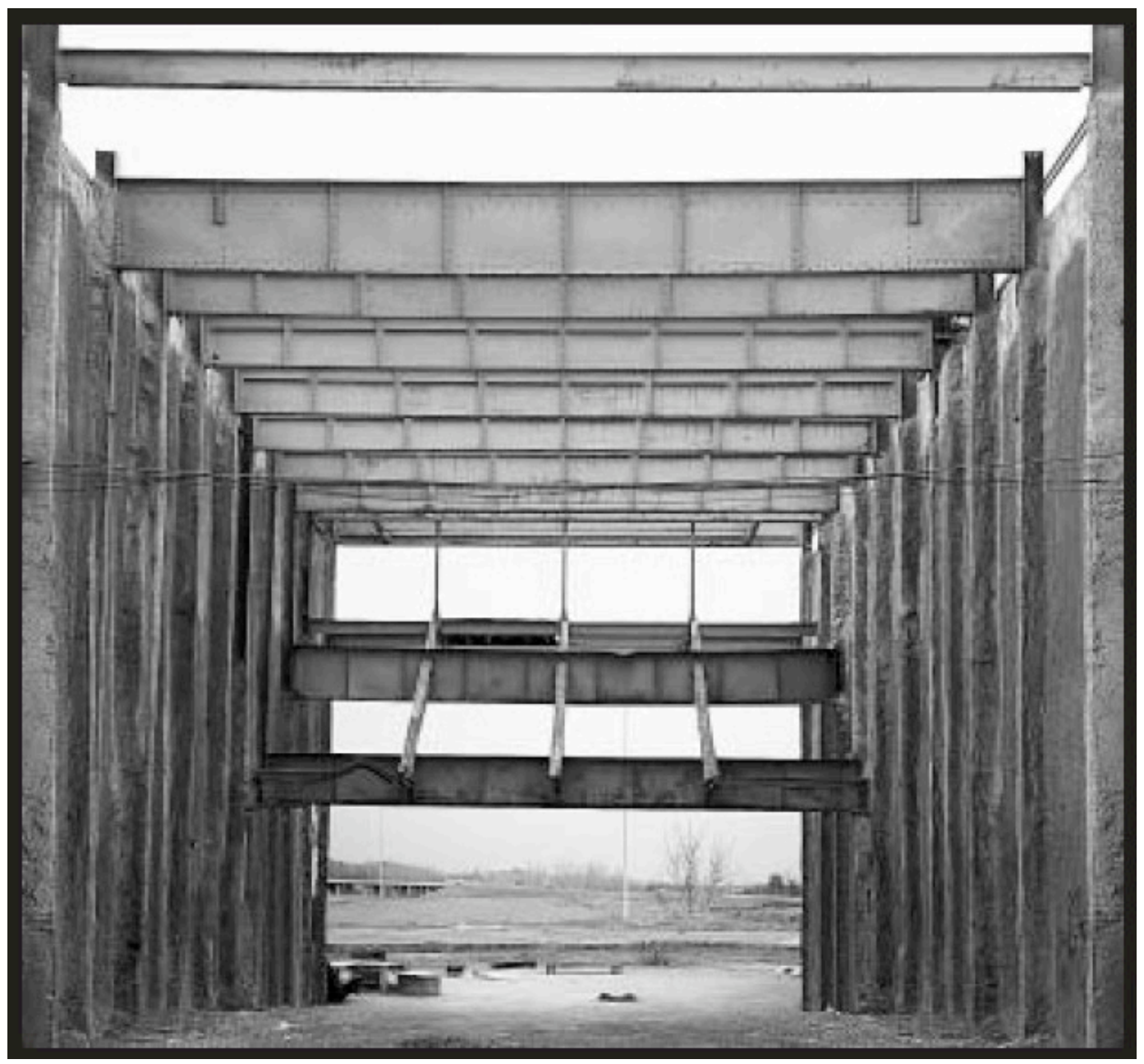

Photo 1 : Isabelle Hayeur, Assise, 2002. $152 \mathrm{~cm} \mathrm{X} 162 \mathrm{~cm}$. Extrait de la Série Fondations. 
Le mythe est un rouage de toute vie collective où il remplit des fonctions vitales : il offre des directions à la pensée et à l'action, il dissipe l'angoisse qui, dans toute société, naît de l'inconnu ou du chaos, il crée des liens entre les groupes, les cultures, les classes, les genres, les races ; il permet de négocier des compromis; il atténue les tensions, les lignes de conflit; il maintient une société unie en temps de crise. Il n'est guère exagéré de dire qu'une société finit toujours par ressembler aux mythes qu'elle se donne. Ce commentaire ne se veut pas une apologie naïve du mythe, mais un simple constat sociologique à partir duquel on peut dégager un critère de définition de la crise.

On pourrait dire qu'il y a crise de la culture lorsque ses mythes fondateurs se défont sans être remplacés. C'est toute la structure de la société qui menace alors de s'effondrer, livrant les individus à euxmêmes, sans horizon, sans direction et sans guide. Vivons-nous une situation de ce genre?

\section{Des données contradictoires}

Que les cultures et les sociétés occidentales soient aux prises avec d'importants problèmes structurels, nul ne songera à le contester. Mais il est non moins évident que le XXe siècle a coïncidé avec des avancées spectaculaires dont nous bénéficions présentement. Le nombre d'États associés au régime démocratique a doublé depuis 25 ans, nous avons vu le déclin de l'eurocentrisme et des formes les plus brutales d'impérialisme et de despotisme, c'est au XXe siècle qu'ont été mises en place les politiques sociales, nous avons également assisté à une expansion spectaculaire de l'alphabétisation et de l'instruction, à une nette amélioration de la condition féminine, à l'abolition de la peine de mort dans de nombreux pays, à l'essor du pluralisme (respect et promotion de la diversité ethnoculturelle), à la mise en place de mesures de protection des droits civiques, à une reconnaissance des minorités, au recul sinon à la fin des censures, etc.

Ces remarques invitent à relativiser le discours de la crise. Elles veulent aussi suggérer que des mythes puissants, porteurs de progrès, sont demeurés actifs jusqu'à très récemment. Il ne s'agit pas de som- 
brer platement dans le jovialisme, mais simplement d'adopter un point de vue plus critique sur une vision peut-être réductrice, de rechercher un diagnostic plus nuancé qui s'accorde davantage avec la réalité. Or, cette réalité apparaît très complexe et il est certes imprudent de vouloir l'inscrire à une seule enseigne.

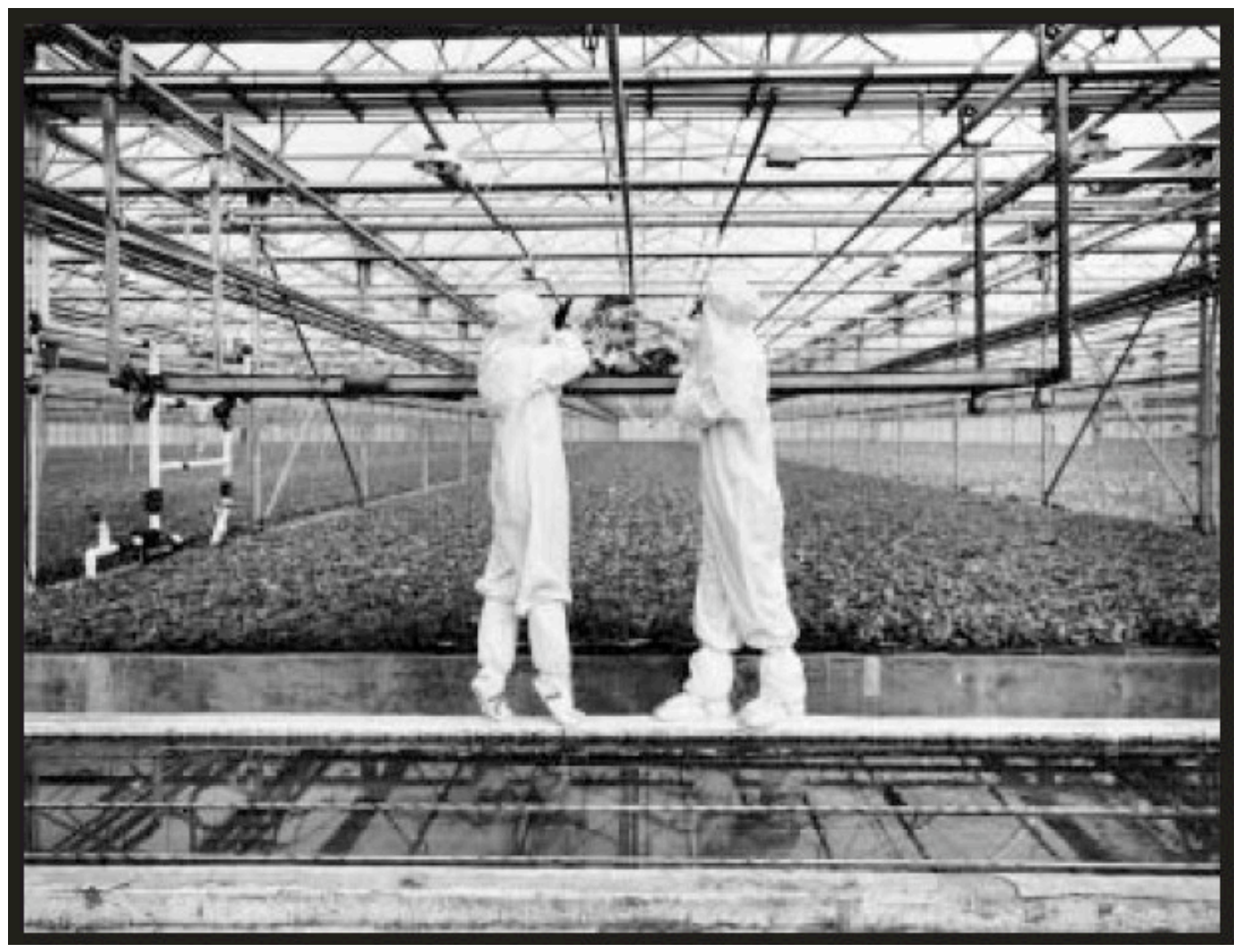

Photo 2 : Eve K. Tremblay. Les Valseuses, 2005. 100 x 125 cm. Extrait de la série Tales without ground.

\section{Et le Québec?}

S'agissant de notre société, on note d'abord que, eu égard à la question examinée ici, elle diffère peu des autres sociétés d'Occident. Structurellement, on y relève à peu près les mêmes traits, les mêmes carences, les mêmes inquiétudes. Mais qu'en est-il en particulier des mythes ? À ce propos, de nombreux Québécois sont victimes d'une illusion: celle d'un déclin brutal au cours des 20 dernières années, 
suivi d'un grand vide symbolique qui nous caractériserait présentement et qui serait à l'origine de bien des maux.

À cette perception, on peut opposer la représentation suivante. À l'époque de la Révolution tranquille, le Québec a procédé à un renouvellement de ses mythes fondateurs, donnant congé notamment aux saints martyrs canadiens, à Dollard des Ormeaux et à la sur vivance. Il s'est donné aussi des mythes projecteurs : la modernité, l'américanité, la laïcité, le développement (le « rattrapage »), l'ascension des Canadiens français dans le monde des affaires, la souveraineté politique, la « québécitude ", etc. Au cours des décennies 1980 et 1990, il est vrai que la plupar $t$ de ces mythes ont perdu de leur mordant parce qu'ils avaient en quelque sorte réalisé leur programme, parce qu'ils avaient livré le potentiel de changement dont ils étaient porteurs. Est-ce à dire qu'ils n'ont pas été remplacés? Bien sûr que non.

Sans qu'on n'y porte assez attention, de nombreux idéaux ou mythes (ou esquisses de mythes) ont émergé depuis. Mentionnons à titre d'exemples: 1'interculturalisme en matière de diversité ethnique, l'ouverture au monde, la citoyenneté, la société civile internationale, le métissage, le trans-culturel, la culture publique commune, la petite nation ingénieuse, créatrice et dynamique, les identités multiples, l'éthique publique comme substitut du religieux et de la morale traditionnelle, le développement durable, l'idéal individualiste de l'« excellence », l'éloge de l'ambivalence et de la fluidité... Il serait, comme on le voit, abusif de parler de vide. Dès lors, où loge la différence par rapport à l'époque antérieure?

La culture québécoise des années 1960 et 1970 était porteuse de ce qu'on pourrait appeler un archémythe, c'est-à-dire une vaste configuration symbolique qui commande et fédère un ensemble de mythes, ou encore : qui structure d'autres mythes et les subsume, si bien que toute avancée enregistrée dans la direction de l'un de ces mythes se traduit par une avancée dans l'ensemble. La figure de l'attelage reproduit assez fidèlement cette dynamique. Or, c'est un phénomène de ce genre qui est absent dans la conjoncture présente. La majorité des mythes en vigueur se présentent désormais à l'état non pas conjugué, mais fragmenté. Si l'on veut, l'atomisation a remplacé l'attelage. Avec le recul du temps, il est aisé de désigner l'archémythe de la Révolution tran- 
quille: l'affirmation nationale des francophones québécois dans l'environnement nord-américain et atlantique. On chercherait vainement une architecture de ce genre aujourd'hui dans notre paysage culturel.

On aurait tort de voir là quoi que ce soit d'anormal ou d'inquiétant. En fait, les mythes se présentent le plus souvent sous une forme fragmentée; c'est plutôt l'archémythe qui est exceptionnel. Il survient parfois dans l'histoire d'une nation ou même d'un continent sans qu'on s'y attende. Il est très difficile d'expliquer son apparition et plus encore de la prévoir ou de la provoquer.

\section{Des constats alarmistes}

La thématique de la crise s'accompagne de constats empiriques apparemment très assurés et pourtant mal fondés. L'identité nationale québécoise est dite en crise alors qu'elle fait l'envie de bien des observateurs étrangers qui la trouvent remplie de dynamisme, capable d'une remarquable flexibilité et en voie d'accommoder d'une façon originale la diversité ethnoculturelle. En se référant à un supposé âge d'or de l'époque de la survivance, on parle volontiers d'une crise de la mémoire collective même si plusieurs indices appuieraient plutôt la thèse contraire (vigueur de l'histoire savante, forte demande dans la culture de masse, floraison de musées, sites, reconstitutions, etc.). Des études sérieuses, crédibles, montrent que la culture des jeunes reste très attachée aux valeurs fondamentales de liberté, de justice, de démocratie, de travail. On sait aussi que le discours donnant les taux de suicide chez les jeunes Québécois comme étant les plus élevés au monde se sont avérés sans fondement (même si le problème doit être considéré comme grave, sans aucun doute). La criminalité au Québec est l'une des plus basses que l'on connaisse en Occident et dans le monde (ce qui est l'un des secrets les mieux gardés qui soient), etc. 


\section{Une nouvelle vision de soi et du monde}

Que retenir de tout cela? Cinq points, en ce qui me concerne. D'abord, et de nouveau, les diagnostics de crise doivent être accueillis avec méfiance, même si la gravité des problèmes ne fait pas de doute. Ensuite, toutes les évaluations et études, statistiques ou autres, doivent être interprétées avec une grande vigilance critique ; la confusion que sèment les nombreuses informations tronquées ou contradictoires accroît la dif ficulté d'une connaissance exacte de soi, d'où la tentation de s'en remettre à des stéréotypes. Troisièmement, il faut s'employer à cerner des problèmes spécifiques, bien déterminés et documentés, afin d'agir efficacement sans se laisser distraire par les bilans à l'emporte-pièce qui noircissent ou blanchissent à outrance. Quatrièmement, la culture savante québécoise s'imprègne peut-être trop aisément de la morosité intellectuelle venue de France (et dont de nombreux Français - nous ne le savons peut-être pas assez — se moquent eux-mêmes). Peut-être devrions-nous nous montrer plus attentifs à d'autres voix venues d'autres parties du monde et porteuses de points de vue, de visions, de sensibilités différents. Enfin, n'est-il pas paradoxal que les deux premières générations de Québécois à avoir enfin accédé massivement à l'enseignement supérieur manifestent à ce point une tendance à la morosité, au dépit, à la démission, à la fatigue ? Après tout, la mondialisation, à laquelle on impute avec raison tant de maux, ouvre également des perspectives sans précédent d'innovation et d'affirmation. Les temps de rupture, comme toujours, sont aussi des temps de recommencement.

\section{Du travail pour les intellectuels}

Ce texte avait pour but de critiquer et récuser le diagnostic de crise, mais sans verser dans un optimisme facile. On a bien raison de s'inquiéter de plusieurs tendances ou glissements en cours dans la société québécoise. On pense aux inégalités sociales et au déficit démocratique croissant (consécutifs à la mondialisation), à la commercialisation et à l'utilitarisme qui menacent d'investir toutes les sphères de la société, à l'expansion des jeux de hasard, à l'infantilisation et à 
l'appauvrissement (teintés de vulgarité) associés à la nouvelle culture de masse, aux relâchements du système d'enseignement, à l'avenir général de l'éthique dans les institutions (publiques et privées), aux intégrismes de tous ordres qui mettent en péril les idéaux pluralistes et l'équilibre de la vie citoyenne, et enfin à l'esprit de démission, au cynisme qui menacent de s'étendre, apportant ainsi une caution bien involontaire à une dérive qu'il faudrait plutôt contenir.

Mais parmi tous les périls, il faut mettre au premier rang la culture marchande, cette monoculture qui menace d'éroder l'espace critique, à savoir une distance salutaire grâce à laquelle une culture - et avec elle, toute une société - peuvent s'amender, se renouveler et progresser.

La discussion sur le thème de la crise peut aisément tourner en une simple querelle sémantique et c'est pourquoi il importe de rappeler la principale question qu'elle recèle : faisons-nous réellement face à une conjonction de tendances destructrices en forme de fatalité, au point que la résignation éclairée constituerait le seul parti raisonnable ? La résignation éclairée, c'est-à-dire le repli dans la lucidité retranchée, dans une révolte retenue, dans les évasions que peuvent offrir le travail quotidien ou la vie de l'esprit, dans la fausse sécurité d'une individualité « auto-fécondée », érigée en barricade - dans tous les cas, dans une forme d'impuissance collective. À l'encontre de ces tentations, il faut plutôt se convaincre que la démission des acteurs constituerait le plus sûr moyen de précipiter dans la crise une société déjà mal en point. Il revient à chacun, et tout particulièrement aux intellectuels, de restaurer les valeurs, les croyances, les idéaux, de concevoir de nouvelles directions pour l'action, de casser la spirale de l'inaction et de l'impuissance. Il faut, en d'autres mots, revenir aux mythes, à la fois pour les promouvoir et les critiquer.

À cet égard, et contrairement à un sentiment de plus en plus répan$\mathrm{du}$, il est utile de rappeler que les intellectuels disposent toujours de puissants moyens pour agir sur la société. Ils sont les virtuoses de l'écrit (qui ne se porte pas si mal) et de la parole (qui se porte encore mieux); ils sont aussi les acteurs principaux, en première ligne, de tout le système d'éducation - ce n'est pas rien. Sans délaisser leur champ, il leur reste à prendre pied, d'une façon ou d'une autre, dans la 
formidable machine que sont les nouvelles technologies de communication de masse. Il y a là des instruments extraordinairement puissants pour qui veut agir directement sur une société ou sur une culture pour la changer. Ce serait une grave erreur que de leur tourner le dos.

\section{Crise ou transition?}

Une crise de la culture ? Le constat est exagéré. Du point de vue des grands repères symboliques, on observe non pas un vide mais une diversification, une grande fragmentation (en particulier dans les mythes). Les changements que nous vivons, cependant, ne se réduisent pas à des ajustements; il s'agit de bien plus que du simple processus, constant et familier, de réaménagement sous couvert de continuité. C'est plutôt le concept de transition qui paraît le mieux refléter la situation présente. Les ruptures y sont nombreuses, profondes, et elles affectent les structures sans instaurer une situation d'anarchie.

Fin du texte 